University of Nebraska - Lincoln

DigitalCommons@University of Nebraska - Lincoln

Faculty Publications, Department of Psychology

Psychology, Department of

April 1989

\title{
Arousal and Physiological Toughness: Implications for Mental and Physical Health
}

Richard A. Dienstbier

University of Nebraska-Lincoln, rdienstbier2@unl.edu

Follow this and additional works at: https://digitalcommons.unl.edu/psychfacpub

Part of the Psychiatry and Psychology Commons

Dienstbier, Richard A., "Arousal and Physiological Toughness: Implications for Mental and Physical Health" (1989). Faculty Publications, Department of Psychology. 216.

https://digitalcommons.unl.edu/psychfacpub/216

This Article is brought to you for free and open access by the Psychology, Department of at DigitalCommons@University of Nebraska - Lincoln. It has been accepted for inclusion in Faculty Publications, Department of Psychology by an authorized administrator of DigitalCommons@University of Nebraska - Lincoln. 
Published in Psychological Review 96:1 (1989), pp. 84-100. Copyright (C) 1989 by the American Psychological Association, Inc. Used by permission. "This article may not exactly replicate the final version published in the APA journal. It is not the copy of record." http://www.apa.org/journals/rev/

\title{
Arousal and Physiological Toughness: Implications for Mental and Physical Health
}

\author{
Richard A. Dienstbier \\ University of Nebraska-Lincoln
}

\begin{abstract}
From W. B. Cannon's identification of adrenaline with "fight or flight" to modern views of stress, negative views of peripheral physiological arousal predominate. Sympathetic nervous system (SNS) arousal is associated with anxiety, neuroticism, the Type A personality, cardiovascular disease, and immune system suppression; illness susceptibility is associated with life events requiring adjustments. "Stress control" has become almost synonymous with arousal reduction. A contrary positive view of peripheral arousal follows from studies of subjects exposed to intermittent stressors. Such exposure leads to low SNS arousal base rates, but to strong and responsive challenge- or stress-induced SNS-adrenal-medullary arousal, with resistance to brain catecholamine depletion and with suppression of pituitary adrenal-cortical responses. That pattern of arousal defines physiological toughness and, in interaction with psychological coping, corresponds with positive performance in even complex tasks, with emotional stability, and with immune system enhancement. The toughness concept suggests an opposition between effective short- and long-term coping, with implications for effective therapies and stress-inoculating life-styles.
\end{abstract}

Confrontations with stressors and challenges evoke central and peripheral physiological arousal. Characterizations of that peripheral arousal traditionally have been negative, but some modem views are more positive. After providing some definitions, I discuss the apparent contradictions between literatures whose basis is an assumption of the harmfulness of peripheral physiological arousal and those whose basis is not.

\section{Definitions}

According to Folkman and Lazarus (1985), the term stress implies "a relationship between the person and the environment that is appraised by the person as relevant to his or her well-being and in which the person's resources are taxed or exceeded" (p. 152). As components of stress, Folkman and Lazarus described threat as "potential for harm or loss," challenge as "potential for growth," and harm-loss as "injury already done" (p. 152). However, because I often emphasize the differences between challenge, on the one hand, and threat and loss, on the other, I use the term challenge separately, using stress to capture only the components of the concept associated with threat and harm/loss.

Much of the preparation of this article was undertaken while the author was a Visiting Scholar at Cambridge University, Cambridge, England. The assistance of many individuals in that Department of Psychology and in various Cambridge University libraries is gratefully acknowledged. The author also thanks James Kinder, Dan Leger, Wes Sime, Ross Thompson, Doris Weimer, Dale Williams, and several anonymous reviewers for useful suggestions, and to Lorraine James and Cathy Oslzly for invaluable help in manuscript preparation. Special thanks are due Martin Hoffman for heroic efforts in obtaining reviews.

Correspondence concerning this article should be addressed to Richard A. Dienstbier, Department of Psychology, University of NebraskaLincoln, Lincoln, Nebraska 68588-0308.
Similarly, "stressor" describes a situation likely to lead to appraisals of threat or harm-loss by a person or, for a nonhuman, to a situation such as receiving electric shocks or swimming in cold water. "Challenge/stress situation" describes the situational side of an organism-situation interaction that could lead to appraisals of challenge (and positive emotions) or of stress (and negative emotions).

Two physiological arousal or neuroendocrine systems are central to this article. "SNS-adrenal-medullary arousal" features the hypothalamus acting through the sympathetic nervous system (SNS) to stimulate the adrenal medulla to release adrenaline; from SNS synapses, noradrenaline is also released. "Pituitary-adrenal-cortical" arousal features the pituitary gland, which releases adrenocorticotropin (ACTH) into the blood, so that ultimately the adrenal cortex is stimulated to release cortisol (the glucocorticoid of primary importance in humans).

"Peripheral physiological arousal" (hereafter "arousal") implies increases above resting base rates of one or both of those arousal complexes, as indicated.

The catecholamines adrenaline, noradrenaline, and dopamine are produced and are active both centrally and peripherally. However, because of the differential importance of those neuroendocrines in central and peripheral function, researchers traditionally have focused on the peripheral catecholamines adrenaline and noradrenaline and on the central catecholamines noradrenaline and dopamine. My use of the terms central and peripheral catecholamines reflects that convention.

\section{Negative Views of Arousal}

Since the early identification of adrenal-medullary responses with "fight or flight" by Cannon (1915/1929) and of adrenalcortical responses with general responses to stressors by Selye 
(1956), peripheral physiological arousal has been regarded negatively. Adaptive advantages of energizing arousal are sometimes acknowledged for nonhumans and for technologically unsophisticated humans by such expressions as "the wisdom of the body." But for modern humans who supposedly have few appropriate physical outlets for such negative emotional arousal, the maladaptive character of arousal is emphasized. Consider, for example, Carruthers's (1981) statement that “men's Stone Age physiological and biochemical responses to emotion have become inappropriate in his Space Age setting, and can pave the way to psychosomatic diseases" (p. 239).

According to such logic, measures of arousal often became the definitive indicators of stress. Those negative constructions of (usually SNS-related) arousal formed the basis for theory and research in both traditional and current research areas. Traditional areas included autonomic balance, psychosomatic medicine, and life events influencing illness. In modern research, investigators explore the negative interactive effects of arousal from challenge/ stress situations and certain personality dispositions (e.g., Type A, and hostility or its suppression) on hypertension, coronary disease, immune function, and cancer.

\section{Positive Views of Peripheral Arousal}

\section{Research With Nonhumans}

Early life experiences. Initially, researchers in this tradition exposed young rats or mice to daily episodes of stimulating or stressful manipulations ranging from handling, or living with an "aunt" of a different species, to electroshock (e.g., Denenberg, 1967; Levine, 1960). As adults, the experimental animals had higher adrenal-gland weights and yet were less fearful or "emotional" when exposed to threats than were nonstressed control animals. (These findings led Hunt, 1965, to suggest that regularly sheltering human children from stressors may be counterproductive for ideal emotional development.)

In later supportive work, researchers found that despite the larger adrenal glands of the previously handled (calmer) animals, they had lower catecholamine and cortisol base rates. In episodes of stimulation or stress, they also showed reduced cortisol responses and sharper catecholamine "spikes" (quicker and higher from base rate, with rapid return to base rate; Meaney et al., 1987; Pfeifer, 1976).

Behavioral suppression. In learned-helplessness experiments (e.g., Overmier \& Seligman, 1967), one control group is exposed to a somewhat controllable stressor, whereas a yoked experimental group with an equal level of aversive stimulation experiences no control. Only experimental-group animals demonstrate behavioral suppression or helplessness in anew avoidance/escape task that is typically presented 30 min later. However, this helplessness dissipates with longer delays between the uncontrollable stressors and the later test. Weiss and his colleagues pursued that observation through a series of experiments to show that "helpless" animals suffered from reduced central noradrenaline (Weiss, Stone, \& Harrell, 1970). Furthermore, exposure to manipulations that induced exhaustion (Weiss \& Glazer, 1975) or to drugs that temporarily reduced central noradrenaline (Glazer, Weiss, Pohorecky, \& Miller, 1975) produced similar behavioral effects (Weiss, Glazer, Pohorecky, Brick, \& Miller, 1975). On the other hand, rats showed no subsequent helplessness when given a monoamine oxydase inhibitor (which prevents depletion of noradrenaline and the other monoamines) before inescapable shock. Short-term neuroendocrine depletion thus seemed both sufficient and necessary for the helplessness effect.

Weiss et al. (1975) reasoned that because severe acute stressors depleted brain catecholamines, then intermittent stress (implying repeated exposure, but with recovery periods) might lead to stress tolerance with resistance to neuroendocrine depletion. Thus for 14 consecutive days, experimental animals were trained by either cold-water swimming, uncontrollable shock, or by chemically induced neuroendocrine depletion (with the monoamine inhibitor tetrabenazine; Glazer et al., 1975). When subsequently subjected to a final stressful session of either inescapable shock, cold swimming, or a final injection of tetrabenazine 30 min before avoidance/escape testing, no performance deficits occurred. In Miller's (1980) terms, these animals were "toughened up." (The concept of "toughness" will be used throughout this article, but its implications will increase as the article progresses.)

When sacrificed after the final inescapable shock episode, toughened animals had high hypothalamic and forebrain noradrenaline levels and higher levels of tyrosine hydroxylase (TH), which indicated greater catecholamine capacity, because $\mathrm{TH}$ is the rate-limiting enzyme in catecholamine synthesis. The brain tissue (in vitro) of toughened animals had slower uptake of noradrenaline (leaving higher noradrenaline concentrations in the tissue). Training with intermittent stressors clearly prevented catecholamine depletion; that resistance to depletion in turn prevented the helplessness response either to subsequent uncontrollable stressors or to chemical depletion. ${ }^{1}$

In this classic series of studies, Weiss and his colleagues studied brain catecholamines; as discussed later, such findings are also relevant to peripheral arousal issues.

Catecholamine influences on retention. When peripheral catecholamines are depleted (through drug manipulations) immediately after a training session, retention of learning is adversely affected (McGaugh, 1983). Similarly, in circumstances in which retention would be facilitated by amphetamines, that facilitation is attenuated in animals whose adrenal medullas have been removed. Conversely, in catecholamine-deficient animals, retention is facilitated by administration of peripheral adrenaline and noradrenaline. (Although it is not known how peripheral catecholamines affect central processes, strong evidence suggests their glucose-stimulating capacities; Gold, 1986). Memory processes are also influenced by ACTH, ACTH fragments, and related peptides; Gold \& Delanoy, 1981).

In combination, these brief reviews show that intermittent ex-

\footnotetext{
${ }^{1}$ The apparent similarities of behavioral suppression in animals and human depression have suggested a model of depression based on central catecholamine depletion. That model is supported by the central catecholamine-generating effects of some antidepressant medication. Although that model is still viable for some reviewers (e.g., van Praag, 1986), the frequently observed irregularities in levels of other neuroendocrines in depression have led to strong competing hypotheses (e.g., Potter, Ross, \& Zavadil, 1985). The connection represented in Figure 2, $\mathrm{m}$ (discussed later in the text) should be interpreted with these caveats in mind.
} 
posure to stressors results in increased peripheral (the early experience literature) and central (the behavioral suppression studies) catecholamine availability. The retention literature serves to further blur distinctions between central and peripheral catecholamine levels; interaction and interdependence between those systems is apparent.

\section{Research With Humans}

Arousal-performance relations. Two decades of largely Scandinavian research have consistently shown positive correspondences between better performance on a variety of tasks and taskrelated catecholamine increases. (As with catecholamine-personality relations, to be discussed, these findings have generally been stronger for men than for women and are found more consistently for adrenaline than for noradrenaline). ${ }^{2}$

For example, sixth-grade Swedish boys and girls whose adrenaline levels increased between a resting movie condition and a math test outperformed those with hormonal decreases; the increasers showed stronger resistance to errors, particularly in later phases of the exam (Johansson, Frankenhaeuser, \& Magnusson, 1973). For Finish high school students, adrenaline increases during an important 6-hr metriculation exam (compared to a control period of nonstressful school work) correlated substantially with exam performance for boys with somewhat lower correlations for girls (Rauste-von Wright, von Wright, \& Frankenhaeuser, 1981).

Similar results are consistently found with adults. Swedish male college students who performed better on a choice-reactiontime task had larger urinary adrenaline increases from base rate to task (Johansson \& Frankenhaeuser, 1973). Similarly, in a 2-hr radar-screen monitoring task, urinary adrenaline and noradrenaline increases over base rate corresponded with performance for American college men and women (O'Hanlon \& Beatty, 1976). For 11 days Ursin, Baade, and Levine (1978) studied men training to become Norwegian Army paratroopers. Catecholamine increases from before jumps to after jumps from a training tower corresponded with positive performance in written technical competence and with jump performance from the training tower and aircraft (Ellertsen, Johnsen, \& Ursin, 1978).

Despite the high difficulty level of some of the tasks in this reviewed literature, these data indicate no curvilinear relations; naturally evoked peripheral catecholamines never seem to be too high for optimal performance.

Arousal-personality relations. Johansson et al. (1973) found that those children whose adrenaline levels increased from base rate to math test (in contrast with decreasers) were more satisfied with school and had better social adjustment and emotional stability, according to their teachers. Similarly, Rauste-von Wright et al. (1981) found that higher catecholamine increases from base rates to metriculation exam corresponded with lower psychosomatic symptomotology and, only for boys, with lower anxiety and higher school achievement and teachers' ratings.

Studying American male medical students, Roessler, Burch, and Mefferd (1967) noted that higher challenge-task catecholamine increases corresponded with Minnesota Multiphasic Personality Inventory (MMPI) ego strength (adaptive capacity or stress tolerance). Forsman (1981) asked Swedish male college students to assess the stressfulness of daily living situations (a day-to-day stress scale). After periods of rest or mild stress, subjects each contributed 17 separate urine samples across a 48$\mathrm{hr}$ period at home and in the laboratory. Increases in adrenaline from rest to stress (in controlled lab conditions) corresponded with lower neuroticism and day-to-day stress scores. The complement of this finding with clinically anxious individuals is that in response to various stimuli, indicators of SNS arousal usually increase less than in normal controls (Lader, 1983).

In conclusion, although the Scandinavian studies cited previously were correlational, research with nonhumans in the areas of early experience and behavioral suppression has shown that the same manipulations that increase emotional stability and stress tolerance also increase central and peripheral catecholamine availability. Thus although causality from catecholamine availability to both personality and performance is not proved, a reasonably strong case can be made.

\section{Reconciliation of Negative and Positive Views}

\section{Different Kinds of Arousal}

The importance of distinguishing between SNS-adrenal-medullary and pituitary-adrenal-cortical arousal is supported by factor analyses of responses to complex situations.

For example, Ursin et al. (1978) obtained separate Catecholamine and Cortisol factors from blood, urine, and performance measures of Norwegian Army paratroopers: The Catecholamine factor (adrenaline and noradrenaline) corresponded with written technical competence and success in jumping and, on high-activity days, with blood glucose levels; the Cortisol factor correlated with defensiveness and with poor performance in jumps from both the training tower and aircraft.

Separate Catecholamine and Cortisol factors were similarly identified for recruits during basic training (Rose, Poe, \& Mason, 1967) and for United States Navy recruits who, as nonswimmers, were required to jump into the deep end of a swimming pool (Vaemes, Ursin, Darragh, \& Lambe, 1982).

\section{Physiological Responses Associated With}

\section{Challenge/Stress Appraisals}

Research with nonhumans. In a range of subjects from rats and mice to primates, exposure to stressors with minimal predictability, control, or feedback (situations of stress, rather than challenge) results in heightened cortisol responses. Such cortisol ele-

\footnotetext{
${ }^{2}$ In many of the studies mentioned herein, the researchers assessed catecholamines in humans with urinary rather than blood or spinal fluid measures. Because only a small fraction (usually less than 5\%) of secreted catecholamines are excreted in urine, urinary assays are not as appropriate for measuring absolute levels as are blood measures. However, in catecholamine infusion studies, urinary measures show a relatively constant relation to the rate of intravenous administration. Similarly, urinary excretion rates correspond roughly to changes in monitored plasma concentrations (see review by Forsman, 1983). The substantial correlations between urinary catecholamine concentrations and personality variables (often from .40 to .50) that have been found by the Scandinavian researchers (e.g., Forsman, 1981; Rauste-von Wright, von Wright, \& Frankenhaeuser, 1981) are an indication of the usefulness of urinary analyses in challenge/stress situations of durations over $20 \mathrm{~min}$.
} 
vations are maintained, not by high activity levels, but rather by a lack of appropriate responses. For example, both infant and mother squirrel monkeys undergoing mutual separation (with no effective responses available) show elevated cortisol, even when activity levels of the infants are suppressed by the presence of a substitute "aunt" (Levine, 1980; Coe \& Levine, cited in Levine, 1983).

When stressful situations are sufficiently extended, they also lead to catecholamine depletion (see the behavioral suppression literature reviewed earlier). However, either perceived or effective coping (defining the situation as challenging) prevents both high cortisol levels and catecholamine exhaustion (Henry, Kross, Stephens, \& Watson, 1976; Miller, 1980). Even the ineffective (for shock avoidance) response of fighting among rats subjected to inescapable shock inhibits catecholamine depletion (Anisman \& LaPierre, 1982). ${ }^{3}$

Research with human subjects. The Scandinavian researchers also explored cortisol relations. With high levels of control in a challenging choice-reaction task (subjects regulating their own stimulus rate, described as "effort without distress"), catecholamines increased, but cortisol responses were below base rate (Frankenhaeuser, Lundberg, \& Forsman, 1980). With a dull vigilance task ("effort with distress"), both adrenaline and cortisol were elevated (Lundberg \& Frankenhaeuser, 1980). Cortisol elevation is particularly high during such understimulation in activity-seeking Type A subjects (Lundberg \& Forsman, 1979).

Similarly, when elderly nursing home residents were taught coping skills and became involved in decision making, their cortisol responses dropped below their previous base-rate levels (Rodin, 1980). There is a personality-cortisol relation as well: Hospitalized children who cope effectively have lower cortisol levels than those who do not (Knight et al., 1979). Ursin, Murison, and Knardahl (1983) noted that heart rate and adrenaline became elevated even in experienced air-traffic controllers, but high cortisol responses developed only in defensive individuals. Ursin et al. (1978) noted similar correspondences between cortisol elevation and defensiveness with paratrooper trainees.

High cortisol base rates are associated with anorexia (Barnes, 1986), depression, anxiety, and neuroticism (e.g., Anisman \& LaPierre, 1982). Anxiety and depression increase with adrenal-cortical-steroid infusion (Persky, 1975), and anxiety fluctuates .according to endogenous cortisol levels (Lader, 1983). Day-to-day fluctuations in fear closely paralleled daily cortisol levels in the paratrooper trainee study (Halse, Blix, Ellertsen, \& Ursin, 1978; Levine, 1978). High levels of cortisol in animals depress neural functioning (Barnes, 1986) and are associated with hippocampal cell deterioration (Meaney et al., 1987). ${ }^{4}$

\section{Timing of Arousal}

Timing issues include (a) base-rate arousal levels and the intensity and speed of arousal increase with the onset of challenge/ stress; (b) the speed of arousal decline after a challenge/ stress episode; (c) the speed of decline across a series of episodes; and (d) the changing levels of arousal components resulting from contin- uous stress. The relation of those facets of the arousal curve with performance, personality, and age will be discussed.

Base rates and speed and strength of onset. Animal research clearly shows that high base rates of pituitary-adrenal-cortical activation correspond with large stress-induced increases (e.g., Meaney et al., 1987). As described earlier, both conditions are problematic. Clearly, an ideal pattern of cortisol arousal is for low base rates and low and delayed cortisol responses with challenge or stress.

The catecholamines present a different pattern. The problems with high SNS-adrenal-medullary base rates are illustrated by A. S. Baum's research with people living near Three Mile Island. Those with chronically elevated catecholamines tended to have poorer psychological adjustment and more health problems (A. S. Baum, 1986; Collins, Baum, \& Singer, 1983). In Forsman's (1981) work with the day-to-day stress scale, overall adrenaline levels (across 17 samples) correlated with higher day-to-day stress scale scores, but catecholamine increases from relaxation to challenge/stress corresponded with positive measures. The early-experience research with rats (Pfeifer, 1976) similarly demonstrated the positive adaptive value associated both with low arousal base rates and, in challenge/stress contexts, with fast and strong SNS-adrenal-medullary arousal generation.

It is not that phasic increases in catecholamines (or cortisol suppression) will be uniformly experienced as pleasant (see the recent review of adrenaline and noradrenaline infusion studies by Sartory \& Ladar, 1981). Rather, when energy-generating catecholamine responses are elicited in the context of potential control, for which effective instrumental coping responses are likely to lead to success, then positive emotional attributions and responses are likely (Dienstbier, 1979).

Speed of arousal decline in an episode. Pfeifer's (1976) earlyhandled (calm) rats showed faster catecholamine decline than did control rats across the several days of a poststress period. With human subjects, several researchers have associated slow poststress catecholamine decline with poor performance and neuroticism (e.g., Eysenck, 1983a; Johansson \& Frankenhaeuser, 1973) and with anxiety (Lader, 1983).

Rapid decline in arousal depends on its quality. It is possi-

\footnotetext{
${ }^{3}$ One of the links (of many possible) between the catecholamine and cortisol systems may be through the inhibition of adrenocorticotropin (ACTH) secretion by brain regions in which noradrenaline is the primary neurotransmitter (Ganong, Kramer, Reid, Boryczka, \& Shackelford, 1976). ACTH production and subsequent adrenal cortical increases are therefore likely results from stress-induced brain noradrenaline depletion (Whybrow \& Silberfarb, 1977).

${ }^{4}$ Although cortisol levels are elevated in most endogenously depressed individuals (with attenuated negative feedback between glucocorticoids and adrenocorticotropin, as evidenced by the dexamethasone test; e.g., McNeal \& Cimbolic, 1986), there is no consensus that elevated cortisol base rates cause depression. Nevertheless, depressed moods follow from cortisol infusion. By way of balance of this negative emphasis, cortisol is necessary for survival; it is involved in controlling inflammation and plays a role in stimulating both glucose and free fatty acids; and it may sensitize cells to the catecholamines and other neuroendocrines. The means of impact of cortisol on physiological functioning are considered by some reviewers to be poorly understood (Donovan, 1985)
} 
ble for peripheral catecholamine arousal to decline very quickly because the half-life of those neuroendocrines in humans is less than $3 \mathrm{~min}$. However, the much longer half-life of 60-90 min for cortisol (Ward et al., 1983) suggests that physiological arousal that is supported by strong pituitary-adrenal-cortical action will not dissipate quickly with challenge/stressor offset.

Decline across episodes. With paratrooper trainees, the rate of decline in catecholamines across training days was positively correlated with performance in both tower and later airplane jumps (Baade, Ellertsen, Johnsen, \& Ursin, 1978). However, this decline across episodes is at least as important for cortisol; recall the associations of cortisol and fear in paratrooper trainees and of cortisol with defensiveness in air-traffic controllers. Yet, both groups sustained daily task-related catecholamine increases that were not associated with distress. Ideally, as coping is mastered, cortisol responses should return to base rate, but peak catecholamine responses should decline only to the level needed to sustain active coping.

Arousal with continuous stress. Continuous stress leads to sustained high cortisol levels and catecholamine secretion exceeding replacement capacity (Anisman \& LaPierre, 1982; Coover, Ursin, \& Murison, 1983). As noted earlier, the stress tolerance of the toughened organism is associated with an ability to suppress the cortisol response and to resist brain catecholamine depletion and the associated behavioral suppression. ${ }^{5}$

In summary, the ideal timing parameters for arousal constructed from these observations should describe the typical arousal pattern for an emotionally stable and competent individual. In comparison with those of less fit individuals, SNS-adrenal-medullary and adrenal-cortical base rates for the fit individual are low, but in a challenge/threat situation, SNS-adrenal-medullary arousal onset is fast and strong, whereas cortisol remains relatively low; arousal decline is fast with stressor offset; and across repeated similar episodes, arousal levels for both kinds of peripheral arousal decline more quickly than in less fit controls (this is particularly apparent with cortisol). If stress is continuous, the fit individual will sustain SNS-adrenal-medullary arousal longer, and both catecholamine depletion and large pituitary-adrenal-cortical responses will be delayed. These parameters of arousal quality and timing add to the characterization of a toughened individual; additional characteristics will be presented in the next section.

Compare this characterization of the toughened individual with the arousal pattern of older organisms. Because older organisms are usually perceived to cope less effectively, particularly in laboratory tasks, their arousal patterns should not conform to the optimal patterns suggested here. Indeed, older rats exposed to cold stress do not adapt as well, generating SNS-adrenal-medullary arousal more slowly and less intensely than younger animals, but arousal decline is slower than in younger animals (McCarty, 1985). In comparable research, in contrast with younger men, older men showed all of these differences (Faucheau, Bourliere, Baulon, \& Dupuis, 1981). Last, as predicted, older rats have higher pituitary-adrenal-cortical base rates and higher adrenalcortical reactivity to stressors (Meaney et al., 1987). When subjected to extended stress, they show more rapid and longer lasting catecholamine depletion (Ritter \& Pelzer, 1978).
The Nomological Net and Other Relevant Research

In this section a more complete description of the toughened individual is developed. A nomological network of research relations is placed around the general hypothesis that various toughening manipulations (see Figures 1 and 2) lead to positive performance and temperament dispositions through a syndrome of physiological mediators.

\section{Manipulations}

"Early experience" implies regular early exposure to stimuli that can elicit strong arousal responses in the young organism. "Passive toughening" implies similar intermittent exposure of mature organisms to shock or cold, to systematic injection of neuroendocrine-depleting drugs, and so on. "Active toughening" implies regular activity such as swimming in cold water, aerobic exercise, and so on. In opposition to these manipulations, "aging," a celestial rather than lab manipulation, should have weakening effects.

\section{Physiological Mediators}

The four mediating physiological factors (see Figures land 2) were introduced earlier. "Peripheral catecholamines" implies catecholamine responsivity, or increased catecholamine availability in challenge/threat contexts. "SNS (beta) sensitivity" suggests that the physiological responses associated with beta-adrenergic receptors are enhanced, with more response per unit of catecholamine. 6

\section{Performance and Temperament Characteristics}

"Performance in challenge" implies success in challenging laboratory and real-life circumstances that require active coping, such as those typically studied by the Scandinavian researchers (e.g., examinations, mental math, and color-word conflict tasks). "Unemotional temperament" implies emotional stability (i.e., low levels of fearfulness in animals and humans and low anxiety, sadness, and/or general distress in humans). "Stress tolerance" im-

\footnotetext{
${ }^{5}$ As indicated in several studies reviewed here, intermittent stress increases concentrations of the enzymes (particularly rate-limiting tyrosine hydroxylase) that build the catecholamines. This process results in greater central and peripheral catecholamine availability.

${ }^{6}$ Physiological responses associated with beta receptors include dilation of blood vessels in muscles and liver, increased heart rate, and increased glycogenolysis and lipolysis (Martin, 1985). Increased catecholamine sensitivity is typically demonstrated by infusion of those neuroendocrines or by study of effects of beta blockers. The increase in the responsiveness of and beta sensitivity to the catecholamines described here is not typical of neuroendocrine adaptation; that is, with adrenocorticotropin, adrenal cortical steroids, and most other neuroendocrines studied, adaptation leads to reduced secretion when one is reexposed to stressors (Sklar \& Anisman, 1981). R. S. Williams, Caron, and Daniel (1984) suggested that this increased catecholaminergic sensitivity is necessary to counter the reduced catecholamine base rates found in aerobically trained individuals. On the other hand, the increased catecholamine base rates in the elderly seem to be associated with their lowered sensitivity to those neuroendocrines.
} 


$\begin{array}{lll}\text { Manipulations } & \begin{array}{l}\text { Physiological } \\ \text { Mediators }\end{array} & \begin{array}{c}\text { Performance \& } \\ \text { Temperament }\end{array}\end{array}$

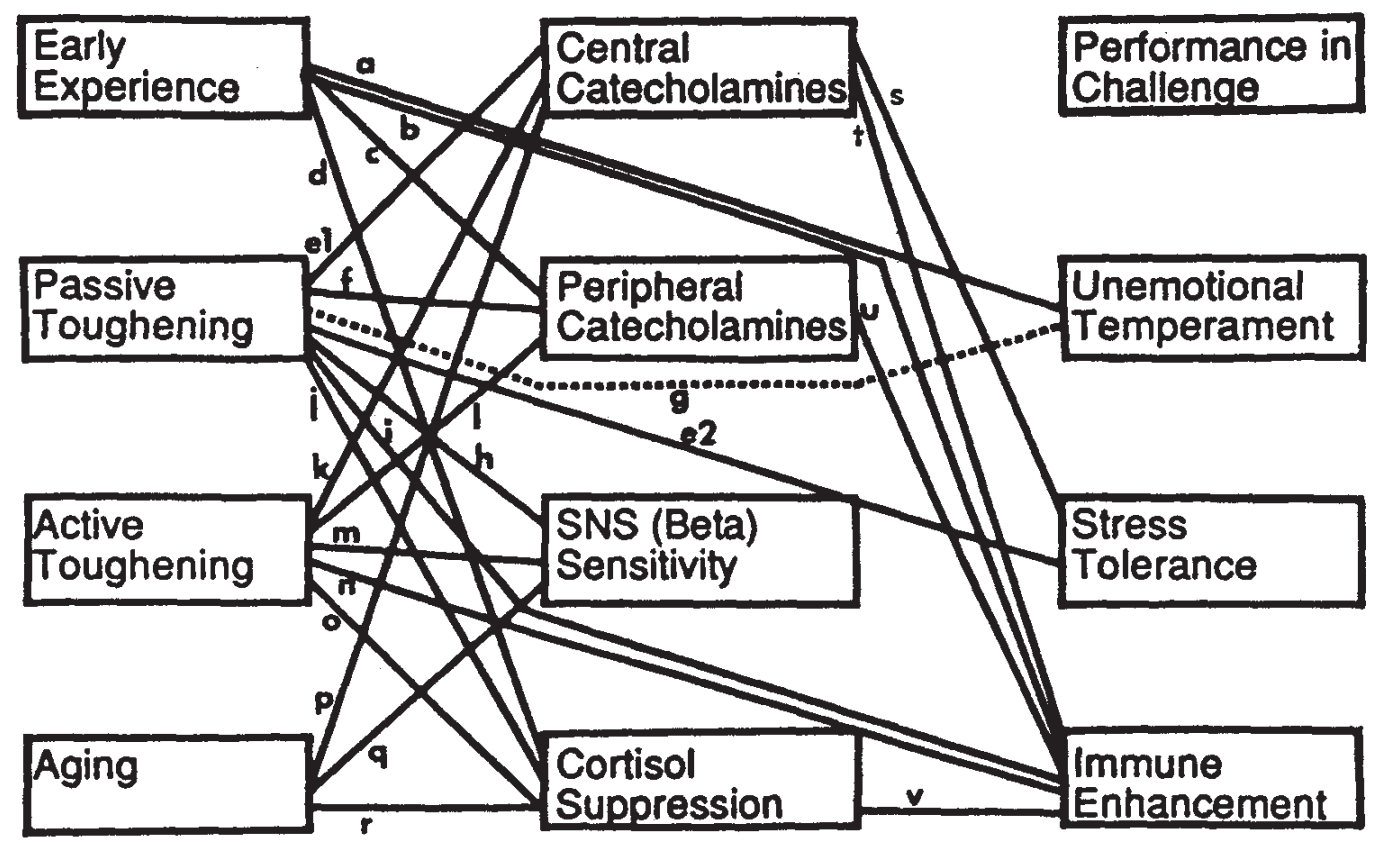

Correlation

\section{Causation}

Figure 1. Animal research showing the relation of three toughening manipulations and aging through physiological mediators to performance and temperament. [The direction of causality indicated by solid lines is uniformly from left to right. Letters in Figure 1 refer to the following studies and reviews: (a) Levine, 1960; Denenberg, 1967; (b) G. S. Solomon, Kay, \& Morley, 1986; (c and d) Pfeifer, 1976;(e1 and e2) Weiss, Glazer, Pohorecky, Brick, \& Miller, 1975; (f) Bhagat \& Horenstein, 1976; (g) Stone, 1968; (h) Bryar, Fregly, \& Field, 1983; (i and j) Sklar \& Anisman, 1981 (review); (k) Brown \& Van Huss, 1973; Brown et al., 1979; (1) Bhagat \& Horenstein, 1976; Alho, Koistinaho, Kovanen, Suominen, \& Hervonen, 1984; (m) Harri, 1979; (n) Sklar \& Anisman, 1981 (review); (o) Starzec, Berger, \& Hesse, 1983; (p) Ritter \& Pelzer, 1978; (q) Greenberg \& Wiess, 1978; (r) Meaney et al., 1987; (s) Glazer, Weiss, Pohorecky, \& Miller, 1975; (t, u, and v) Sklar \& Anisman, 1981; Calabrese, Kling, \& Gold, 1987 (both reviews).]

plies resistance to exhaustion or depression for humans and resistance to helplessness for nonhumans. These three categories are not mutually exclusive.

The "immune enhancement" category is considered later in the Arousal and Health section.

\section{The Model}

According to this physiological mediation model, (a) each of the toughening manipulations should influence each of the physiological mediators, and (b) each of the physiological mediators is, in turn, a theoretical cause of the performance and temperament characteristics. The overarching relation of causality from each of the four manipulations listed to each of the performance and temperament variables follows logically and is also predicted. ${ }^{7}$

\footnotetext{
${ }^{7}$ The relations of this last hypothesis between manipulations and performance and temperament characteristics do not provide direct evidence for the arousal-mediation aspects of the model, but such relations add substance to the nomological net. In other words, when a manipulation influences both physiological processes and performance or temperament, that combination of relations suggests that the physiological process is a likely mediating variable between the manipulations and performance or temperament. If relations between manipulations and performance or temperament were not found, the model would be disconfirmed.
} 


\section{Manipulations Physiological Performance \& Mediators Temperament}

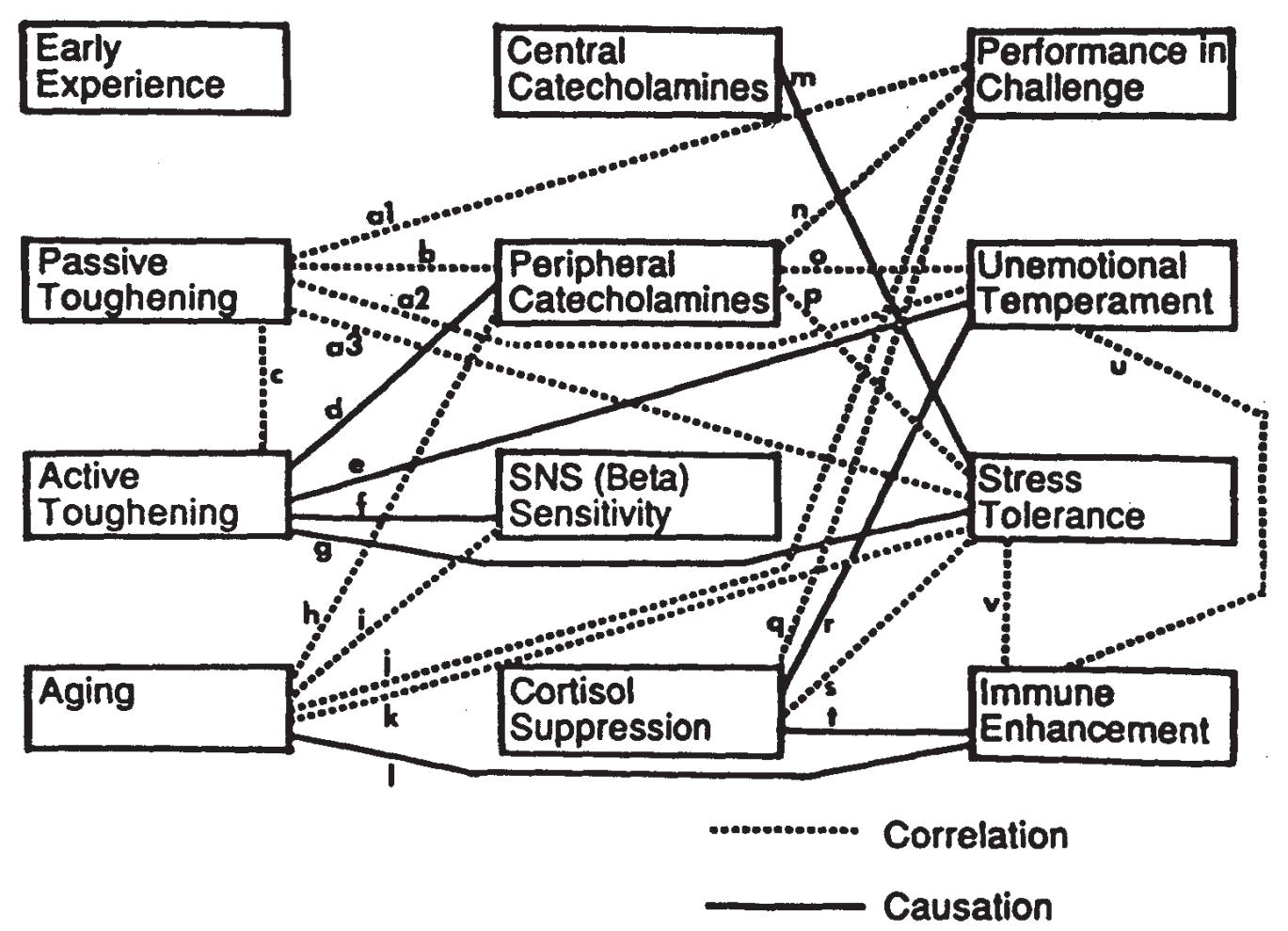

Figure 2. Research with human subjects showing the relation of three toughening manipulations and aging through physiological mediators to performance and temperament. [The direction of causality indicated by solid lines is uniformly from left to right. Letters in Figure 2 refer to the following studies and reviews: (a1, a2, and a3) Dienstbier, LaGuardia, \& Wilcox, 1987; (b) Sklar \& Anisman, 1981 (review); (c) LeBlanc, Côté, Dulac, \& DulongTurcot, 1978; E. Baum, Brück, \& Schwennicke, 1976; (d) Dienstbier, LaGuardia, Barnes, Tharp, \& Schmidt, 1987; Ehsani, Heath, Martin, Hagberg, \& Holloszy, 1984; Sinyor, Schwartz, Peronnet, Brisson, \& Seraganian, 1983; (e) Dienstbier, 1984 (review); (f) Krotkiewski et al., 1983; LeBlanc et al., 1977; (g) McCann \& Holmes, 1984; (h, i, and j) Faucheau, Bourliere, Baulon, \& Dupuis, 1981; (k) Anisman \& LaPierre, 1982 (review); (1) Calabrese, Kling, \& Gold, 1987 (review); (m) Anisman \& LaPierre, 1982 (review); (n) Scandinavian research cited in text; Ursin, Baade, \& Levine, 1978; (o) Scandinavian research cited in text; (p) Frankenhaeuser \& Patkai, 1965; Anisman \& LaPierre, 1982; (q) Ursin et al., 1978; (r) Persky, 1975; Lader, 1983; Knardahl \& Ursin, 1985; (s) Anisman \& LaPierre, 1982 (review); (t) Sklar \& Anisman, 1981; Calabrese et al., 1987 (reviews); (u) Ursin et al., 1984; Sklar \& Anisman, 1981 (review); (v) Sklar \& Anisman, 1981 (review).]

Figures 1 and 2 are included merely to provide a quick visual image of the relations and gaps in this nomological net; the reader need not study the figures to follow this presentation.

\section{Research Confirmation of the Model}

Early experience. The research on early experience for animals was reviewed earlier. In work with children who have faced extreme stress, researchers have focused on the social parameters that may relate to differences in their resilience (e.g., Garmezy,
$1983)$; it is difficult to extract information relevant to my thesis from that work.

Passive toughening. The work of Weiss and his colleagues, reviewed earlier, illustrates the impact of repeated exposure to cold and shock on protecting against depletion of central catecholamines (Figure 1, e1) and on increasing stress tolerance in nonhumans (Figure 1, e2). Long-term exposure to cold also results in increased levels of the precursors of the catecholamines in adrenal medullary tissue, in increased catecholamine levels in plasma and urine in rats (Bhagat \& Horenstein, 1976; see Figure 
$1, \mathrm{f}$ ), and in increased catecholamine production in humans (Sklar \& Anisman, 1981; see figure 2, b). Effects from cold environments on catecholamine sensitivity and responsivity have been noted with nonhuman subjects (Bryar, Fregly, \& Field, 1983; see Figure 1, h). This increased sensitivity of the body to catecholamines occurs in direct proportion to the cold adaptation level of the organism (Jansky, Mejsnar, \& Moravec, 1976) and is considered the main mechanism for long-term adaptation to cold (LeBlanc, 1976). Last, thermal tolerance (in both high and low ambient temperatures) has been shown to correlate with lower emotionality in rats (Stone, 1968; see Figure 1, n).

In order to establish relevant relations between thermal tolerance and temperament in humans, Dienstbier, LaGuardia, and Wilcox (1987) developed and validated (in temperature-controlled environments) self-rating scales for cold tolerance and heat tolerance. Cold tolerance was associated with lower emotionality (figure 2, a2) and less depressed mood (figure 2, a3), but with greater sensation seeking, activity, and vigor (figure 2, a1).

Active toughening. Physical fitness through regular aerobic exercise is particularly important as a possible means for selfregulated toughening. Relevant relations are therefore explored here in some detail.

Although there is a substantial literature concerning the overarching relation from aerobic conditioning to reduced emotionality, most studies have not overcome the confounding of factors such as subject expectations or changed nutritional and sleep patterns. Nevertheless, my analysis (Dienstbier, 1984) is that although no single study can be considered definitive, a review of the best of the many studies in this area shows consistently reduced emotionality, anxiety (figure 2, e), reduced depression (figure 2, g), and even reductions in some of the physiological and psychological indicators of Type A personality (Blumenthal, Williams, Williams, \& Wallace, 1980).

Increased beta-adrenergic sensitivity results from both active and passive toughening manipulations. Relevant experimental studies have been undertaken with nonhumans (Harri, 1979; see Figure 1, m), and experimental studies (Krotkiewski et al., 1983) and correlational studies have been done with humans (LeBlanc et al., 1977; LeBlanc, Côté, Jobin, \& Labrie, 1979; Figure $2, \mathrm{~g}$ ). The inhibition of this training-induced beta sensitivity by beta blockers suggests that it is increased catecholamine exposure that is necessary to stimulate increased catecholamine sensitivity (Harri, 1979). ${ }^{8}$

Research with rats has shown increased brain noradrenaline several days after the end of multiweek exercise training (Brown et al., 1979; Brown \& Van Huss, 1973; see Figure 1, k) and pituitary-adrenal-cortical suppression from similar programs (Starzec, Berger, \& Hesse, 1983; see Figure 1, o). Similar peripheral effects (adrenal-gland catecholamine precursors and plasma and urinary catecholamines) have been achieved with both active and passive (e.g., cold and other stressors) toughening manipulations (Bhagat \& Horenstein, 1976; see Figure 1, f and 1). Similarly, in human exercise-trained cardiac patients (Ehsani, Heath, Martin, Hagberg, \& Holloszy, 1984) and in exercise-trained healthy subjects (Hull, Young, \& Ziegler, 1984; see Figure 2, d), higher catecholamine levels followed peak exercise episodes (in comparison with base rates before training), indicating higher peripheral catecholamine capacity.
To establish catecholamine responsivity as a likely intervening variable influencing psychological processes, researchers should demonstrate that this increased catecholamine responsivity is manifest in response to psychological challenge/stress situations.

One relevant correlational study has shown higher plasma noradrenaline levels for physically fit subjects (in comparison with nonexercising controls) after challenging mental tasks (Sinyor, Schwartz, Peronnet, Brisson, \& Seraganian, 1983), whereas in another, Hull et al. (1984) found null results. Using an experimental approach in a series of three studies, Dienstbier, LaGuardia, Barnes, Tharp, and Schmidt (1987) found that college students who had undergone a semester of aerobic running had increased urinary catecholamines after mental challenge/stress situations, in comparison with sedentary controls and in comparison with themselves before aerobic training. ${ }^{9}$

Similarities of active and passive toughening. The nearly identical impact of these two classes of manipulations on other relevant variables is evident from Figures land 2. A link between them (Figure 2, c) is also established by several studies. Men with a history of aerobic exercise training have less physiological responsivity to cold (e.g., less skin cooling and blood pressure increases; LeBlanc, Côté, Dulac, \& Dulong-Turcot, 1978), and they adjust to cold more easily than do sedentary controls (when adjustments are made for proportion of body fat; E. Baum, Brück, \& Schwennicke, 1976).

Aging. As predicted, all effects for aging are opposite to those of the three other manipulations. Reduced beta-receptor sensitivity has been noted in older animals (Greenberg \& Wiess, 1978; see Figure 1, q) and, along with a less intense SNS-adrenal-medullary spike with various stimuli, in older humans as well (Faucheau et al., 1981; see Figure 2, i). The remaining relations between aging and the other variables of Figures 1 and 2 were described earlier.

${ }^{8}$ Although increased physiological sensitivity to catecholamines results from aerobic training, details of this adaptation are not completely clear; that is, whereas R. S. Williams, Eden, Moll, Lester, and Wallace (1981) found increased beta-receptor sensitivity in only skeletal (not heart) muscle after aerobic training in human subjects and R. S. Williams, Caron, and Daniel (1984) found similar results in rats, others have found heart sensitivity increases. Even sympathetic nervous system nerve fiber densities have been increased in the hearts of rats trained by running throughout their adult lives, in comparison with untrained rats (Alho, Koistinaho, Kovanen, Suominen, \& Hervonen, 1984). Differences between training animals for several weeks by R. S. Williams and his colleagues and the extensive life-long training of the rats by Alho et al. may explain why heart tissue was affected in the research of the latter group. Very specific predictions from this work to humans would be risky.

${ }^{9}$ In accordance with traditionally negative views of arousal and the observation that aerobically trained individuals are emotionally stable, a number of researchers have hypothesized reduced cardiovascular reactivity for aerobically trained individuals in challenge/ stress situations. Although only one correlational study suggested such reduced reactivity, the only experimental study of the group suggested opposite results. A brief review of that literature is available on request. 
In summary, the many similarities between the three toughening manipulations suggest that they be aggregated. According to the reviewed nonhuman and human studies combined, toughening is causally related to all four of the physiological mediators and to the three performance and temperament dimensions (with the exception of only correlational relations with performance in challenge). The physiological mediators are similar candidates for consolidation, insofar as central and peripheral catecholamines, beta-adrenergic sensitivity to the catecholamines, and pituitaryadrenal-cortical suppression all follow from the same manipulations. Last, the interrelations between the first three performance and temperament characteristics are obvious, similarly suggesting consolidation.

With those consolidations, the pattern of data suggests strongly that training with toughening manipulations leads to physiological toughness in the form of resistance to central catecholamine depletion, peripheral catecholamine responsivity, increased beta-receptor sensitivity, and cortisol suppression, and that those physiological parameters lead to positive characteristics of performance, temperament, and stress tolerance. However, because in no single study or even a single program of research can investigators examine all of these relations in concert, this analysis may be considered somewhat speculative. Hereafter, "toughening" will refer to the top three manipulations described in the figures. The physiological pattern developed earlier defines the arousal pattern of a tough or toughened organism; this syndrome also subsumes the timing parameters, discussed in the previous section.

\section{Arousal, Energy, Appraisal, and Coping}

Given that toughness is important for effective coping at the physiological and psychological level, how is that beneficial impact achieved?

\section{Arousal and Coping: Physiological Issues}

Catecholamine influence on mental activity. It is well established that peripheral arousal affects mental processes. McGaugh's (1983) work on peripheral influences on animal learning provides impressive evidence. But how are those impacts achieved?

Although there is some evidence of correspondence between peripheral and brain concentrations of catecholamines, ${ }^{10}$ a most important function of peripheral catecholamines (independent of central levels) is the stimulation of energy for the central nervous system and for the muscles. Glucose is the fuel of the nervous system (Eide \& Atterås, 1978), and the brain is a major energy consumer, using $20 \%$ of the oxygen acquired by the lungs of a resting human (C. U. M. Smith, 1970). This energy consumption increases substantially when significant mental activity is undertaken. For example, increased cerebral blood flow (20\% over resting) and brain oxygen use (30\% over base rate) occur during challenging mental activities such as mental math (Brod, 1970).

Both peripheral catecholamines improve the blood flow to the brain and influence blood glucose levels (Krotkiewski et al., 1983) but blood glucose levels are regulated much more closely by adrenaline (Martin, 1985). (There is normally a negative feed- back loop between adrenaline and glucose, and they therefore correlate in blood only under high-arousal conditions; Eide \& Atterås, 1978.) Adrenaline also stimulates heart rate increases. Thus the association of (primarily) adrenaline with mental challenge/ threat (noted in the Scandinavian research) is adaptive, compensating for vascular resistance decreases in the brain with increased blood flow and stimulating glucose release into the blood for use by the brain.

Glucose availability increases after toughening. Catecholamine infusion studies show higher blood glucose levels in humans after training (Krotkiewski et al., 1983) and in comparison with sedentary control groups (LeBlanc et al., 1977).

Catecholamine influence on muscle activity. Glucose may be the fuel of the nervous system, but increases in free fatty acids (and cholesterol) and blood pressure increases are also stimulated by SNS-adrenal-medullary arousal.

Noradrenaline is more involved (than adrenaline) in regulation of the free fatty acids (and, with thyroxine, in regulating the conversion of fats to energy; Jansky et al., 1976). With the SNS, noradrenaline plays a role in blood flow redistribution through capillary constriction that results in net blood pressure increases. Muscular activity is thereby facilitated because the muscles can utilize the fats as fuel and require massive blood supplies during major activity. Noradrenaline also facilitates neuromuscular transmission by increasing the sensitivity of skeletal muscle membranes to acetylcholine, the neurotransmitter of the voluntary muscles (Jansky et al., 1976). Thus noradrenaline effects are ideally suited for active muscular behavior and are found to correspond very directly with physical activity levels (Martin, 1985).

These observations substantiate the general finding that arousal underlying physical activity (or stimulated by physical stressors) is noradrenaline intensive, whereas that underlying mental activity is relatively higher in adrenaline. (There are exceptions, such as high adrenalin levels in aerobic activity; Frankenhaeuser, 1979; Ward et al., 1983.)

\footnotetext{
${ }^{10}$ There are several possible avenues for such brain-body catecholamine correspondences. McGaugh (1983) suggested several possible means of impact from peripheral concentrations to brain: There may be sufficient passage of catecholamine through the blood-brain barrier (BBB; in part because BBB permeability may be influenced by hormonal action); BBB passage of effective metabolic products or molecular fragments may occur; or BBB permeability may differ sufficiently between brain regions so that some regions may receive sufficient catecholamine influence. Peripheral catecholamine release may correspond with release in the brain (Carruthers, 1981). Such correspondences are observed and may be important. For example, there is a correspondence between central and peripheral changes with age in monoamine oxydase (MAO) concentrations (MAO degrades the catecholamines). Similarly, in depressed people there is a correspondence between low levels of normetanephrine (a peripheral metabolite of noradrenaline) and reduced MHPG (a central nervous system noradrenaline metabolite, though the lower MHPG levels are not uniformly found; Anisman \& LaPierre, 1982). In certain patient groups, sizable correlations are found between cerebrospinal fluid and plasma noradrenaline (Potter, Ross, \& Zavadil, 1985).
} 


\section{Interactions of Physiological and Psychological Coping}

In his theory of coping with stressors, Lazarus (1968) suggested two appraisal levels. Recognition that the situation is important and potentially taxing leads to primary appraisals of challenge, threat, or harm-loss, but a secondary appraisal of one's coping resources may cause revisions in the primary appraisal. In regard to coping resources, Lazarus and his co-workers (e.g., Folkman, 1984) recognized a role for "health, energy, and stamina"; however, skill has been emphasized. A goal in this section is to describe how arousal and energy contribute to secondary appraisals of coping potential.

Although this involves, in part, an obvious substitution of "energy" concepts for "skill," that substitution must address the questions of (a) whether only certain kinds of arousal will lead to positive secondary appraisals and (b) whether very high arousal levels lead to negative emotional responses that would be incompatible with positive secondary appraisals.

The arousal quality question (a) is obviously answered by the distinctions developed earlier; that is, only the components of the tough physiological pattern (in contrast with the weak physiological pattern, dominated by pituitary-adrenal-cortical arousal) have been empirically linked with challenge and with associated positive emotions. The question of negative emotional responses to high arousal (b) was addressed in part by Gal and Lazarus (1975), who noted that when methods of coping were available (challenge/threat situations), even very high arousal levels failed to elicit discomfort and negative emotion. Conversely, negative emotional responses occur in high-arousal situations in which active coping methods are not available (harm-loss).

As an individual acquires coping skills, the intense arousal that originally accompanies learning in very important situations is no longer necessary to motivate the search for relevant information and behavior; one sees such transitions to lowered arousal in avoidance learning in animals (e.g., R. L. Solomon \& Wynne, 1954), and in skill-acquisition studies with phobic humans (e.g., Bandura, Reese, \& Adams, 1982). But some situations may continue to require energy-demanding behavioral or mental responses. In such circumstances, peripheral arousal will continue to be required. When toughening has been achieved, then the energy needed to cope in such challenge/ stress situations is readily available. With awareness of that energy, subjects are likely to appraise coping as easy and successful. With such appraisals, subjects enter a positive spiral involving physiology (energy and an awareness of it) and positive appraisal. for the awareness that one can cope with the situation and an expectation of success should result in the arousal pattern associated with toughening (which should heighten awareness of energy and thus dispose one to even more positive emotions and appraisals, etc.). In short, energy stimulates positive appraisals that modify arousal leading to more energy, and so on (see Figure 3). The short- and long-term causal connections in Figure 3 portray the interrelations among some of the behavioral, physiological, and psychological variables described here (and later). However, the figure is meant to be neither exclusive nor definitive.

On a long-term basis, tough individuals will find fewer situations that cannot be mastered and hence fewer situations that evoke strong negative emotional responses; such an individual will be labeled by self and others as having an "emotionally stable" personality.

\section{Arousal and Health}

Our textbooks tell us that life "events" of a negative or positive nature will lead to illness, stress will lead to immune system deficiencies, and the physiological consequences of even SNSadrenal-medullary arousal (e.g., free fatty acid and cholesterol release; increases in heart rate and blood pressure) will lead to hypertension and cardiovascular disease. These observations suggest that by experiencing physiological arousal in (mostly) .lowactivity situations, we relatively sedentary humans will eventually pay the consequences of ill health. How unfortunate it would be if toughness, associated with positive performance and temperament, should be so costly to physical health.

But I argue in this section that toughness corresponds with positive health status and that with severe or continuous stressors, organisms that are not tough are more likely to suffer adverse health consequences.

\section{The Life "Events" Literature}

The lumping together of both negative and positive life changes or events into single scales (Holmes \& Rahe, 1967) clearly reflected the traditional negative view of arousal. The underlying concept is similar to Selye's (1956) "eustress," a term implying that (with a positive event) even without negative emotional responses, the underlying physiological arousal will extract costs and require adaptation similar to that required by more distressing stressors.

But the life events literature in general (e.g., Kasl, 1983) and the idea of positive events causing illness in particular (e.g., Rabkin \& Struening, 1976) have been heavily criticized and modified. Researchers do not find correlations between positive events and illness (see the review by Thoits, 1983), and in major prospective studies, investigators found that only life events causing discord were related to later illness incidences (e.g., Theorell, 1976) or to later psychological problems such as depression (Anisman \& LaPierre, 1982).

\section{Occupational Stress}

The study of occupational stress has undergone similar transitions. It is no longer assumed that there is a simple relation between the degree of challenge or demand in a job and unhealthy responses; current research indicates that only in the context of low job discretion or control does high job demand lead to exhaustion, psychosomatic illness, and/or depression (Karasek, Russell \& Theorell, 1982; Thorsrud, 1983).

\section{Immune System Function}

Modern research supports these more limited conclusions that immunity is suppressed primarily by events that are experienced negatively (i.e., threat and loss). In an excellent review, Sklar and Anisman (1981; see also Calabrese, Kling, \& Gold, 1987) noted that most acute or short-term laboratory manipulations of non- 

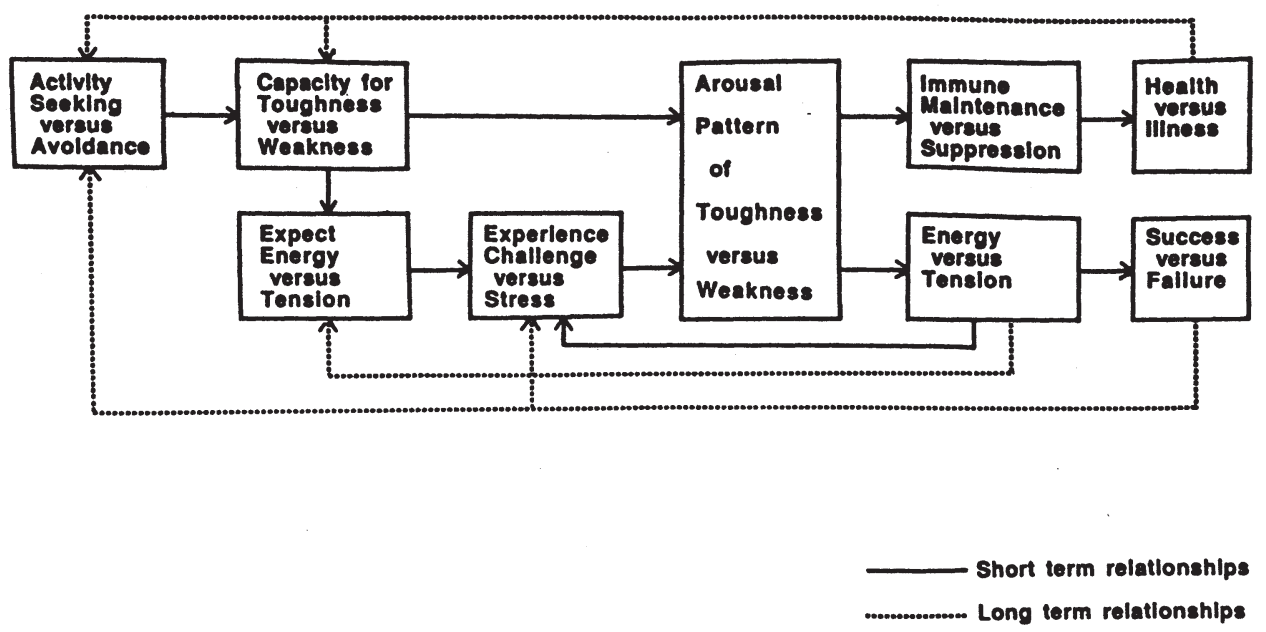

Figure 3. Interrelationships between toughness (versus weakness) and the behavioral, psychological, and physiological concomitants.

human subjects that are usually classified as stressors (including shock, exposure to cold, or social stresses such as crowding) tend uniformly to cause suppression of immunity and to promote the induction, growth, and metastases of cancer. Relatively continuous real-world stressors such as living near Three Mile Island (A. S. Baum, 1986) and bereavement similarly reduce immune system functions in the blood.

Personality factors may interact with such stressors. For example, Ursin et al. (1984; see Figure 2, u) found that school teachers high in neuroticism and with high job stress had lower levels of three salivary immunoglobulins (the primary defense mechanisms protecting against respiratory infection) than did individuals low in both dimensions." Similarly, depression is associated with illness susceptibility and immune system suppression (Calabrese et al., 1987; Sklar \& Anisman, 1981; see Figure 2, v).

The physiological mediators of this model show similar relations to immune function. Apparently in order to reduce injury-induced inflammatory and immune responses, cortisol generally suppresses immune function by inhibiting the secretion of lymphokines (including interferons and interleukins) and thereby depressing helper T-cell functioning (Calabrese et al., 1987; see Figure 1, v, and Figure 2, t). On the other hand, central and peripheral catecholamine availability enhances important aspects of immune function (e.g., natural killer cell activity enhancement by infused noradrenaline; G. S. Solomon, Kay, \& Morley, 1986; Sklar \& Anisman, 1981; see Figure 1, t and u).12

These relations suggest that toughness is associated with immune enhancement. Predictably, the manipulations that lead to toughness have the same positive relation with immune function as with the performance and temperament variables, whereas aging has the predicted inverse relations (Calabrese et al., 1987; see Figure 2, 1). Specifically, early handling of rats (G. S. Solomon et al., 1986; see Figure 1, b), and intermittent exposure to most laboratory stressors (from shock to cold, but not to social stressors) result in enhanced immune function (e.g., enhanced interferon production) and resistance to all phases of cancerous growth. Such prophylactic effects from programs of training with inter- mittent stress (and continuous sound stress) are enhanced if the animals have some control over the stressors (G. S. Solomon et al., 1986) and if stress training occurs before or soon after exposure to experimentally induced pathogens (Sklar \& Anisman, 1981; see Figure 1, i and n).

With the interaction between these psychological and physiological processes in mind, consider that there may also be a psychologically mediated immune vulnerability in individuals who are not tough. The awareness of disease onset, like the physical manifestations, is a potential stressor that may stimulate catecholamine depletion and cortisol increase; with less resistance to those neuroendocrine effects, immune suppression will be greater in the untoughened individual.

\section{Type A Personality}

Under many circumstances, Type As seek more challenge ( $\mathrm{T}$. W. Smith \& Anderson, 1986), set higher goals for themselves, and work harder than do Type Bs (Frankenhaeuser et al., 1980). There is clearly a link between the Type A personality and coronary heart disease (CHD; R. B. Williams, 1986). If that link is mediated by increased SNS-adrenal-medullary reactivity, as com-

${ }^{11}$ Opposed to the direction of these studies, Eysenck (1983b) reviewed several studies on the relation of personality dimensions with several types of cancer and found that neuroticism correlates negative[y with lung cancer incidence. But in their more extensive review, Sklar and Anisman (1981) suggested that despite problems in interpreting many human studies, inability to cope with stress is associated with higher cancer incidence.

12 Although it is clear that adrenal-cortical neuroendocrines broadly suppress immune responses, immune-system responses to the catecholamines are more complex. Although the recent literatures cited here have emphasized catecholamine-related immune enhancement, immune suppression from beta-adrenergic agonists has been noted. Resolution of these differences will undoubtedly depend on analyses of dosage levels and specific impacts on elements of the immune system. 
monly suggested (Matthews et al., 1986), my positive view of that arousal is threatened. But a number of considerations suggest that neither frequent challenge seeking nor the pattern of arousal associated with toughness lead to CHD.

Besides challenge seeking, Type A measures correlate with and/or assess other dimensions, including tension (Eysenck \& Fulker, cited in Eysenck, 1983b), neuroticism (Bass, 1984), hostility, and anger suppression. Some researchers who have separated various dimensions have found no link between challenge seeking and CHD; for example, when the three Type A components of hostility, anger suppression, and explosive speech are separated, only the first two are found to correlate with CHD (R. B. Williams, 1986). In a current review and meta-analysis of studies conducted between 1945 and 1984 that linked personality variables with CHD, Booth-Kewley and Friedman (1987) concluded that the CHD-prone individual is characterized by "one or more negative emotions," rather than as a "hurried, impatient workaholic" (p. 343).

Challenge seeking may be safe, but what about the association of CHD with both cardiovascular and autonomic reactivity to stressors in humans and nonhumans (e.g., Manuck \& Krantz, 1986)? Reviewers of studies of monkeys (e.g., Clarkson, Manuck, \& Kaplan, 1986) and of humans (e.g., Goldstein \& McDonald, 1986; Ursin, 1978) have agreed that health risks follow heightened arousal over long time periods (months or years), which suggests the importance of low base rates and fast recovery. Although in studies with Type A persons researchers frequently find greater reactivity to various stimuli (properly defining reactivity by increases from base rate to stressor condition), few provide catecholamine or cortisol information, and "with few exceptions, reactivity studies do not even discuss recovery data " (Matthews, 1986, p. 463).

Unlike the tough individual's fast return from challenge/ threat arousal to base rates, described earlier, Type As seem to have slower SNS-adrenal-medullary recovery, as suggested by slower T-wave response recovery after noradrenaline infusion ( $R$. B. Williams, 1986).

Last, the major health risk from being Type A may be associated more with pituitary-adrenal-cortical arousal than with the pattern associated with toughness. Ursin and Knardahl (1985) noted that Type As with family histories of cardiovascular disease had higher cortisol levels than did other Type As. R. B. Williams (1986) similarly noted that although Type As gave higher adrenaline and noradrenaline responses to mental math (than did Type Bs), their cortisol differences were even greater. In a review, Herd (1986) cited more experimental evidence for the involvement of cortisol than for the catecholamines in fostering the vascular conditions leading to heart disease.

In conclusion, although the Type A disposition has been shown to be associated with CHD, a challenge-seeking disposition is apparently not a health risk; nor is a toughened arousal capability a likely mediator of CHD.

\section{Conclusions}

\section{The Concept of Toughness}

The initial form of the toughening concept was based on the early-experience literature and on the research by Weiss and his colleagues with behavioral suppression. Around the relations explicated in those literatures, reviews and key studies were presented to show links between (a) an array of manipulations that lead to toughening (and aging, which attenuates toughness) and (b) the four physiological mediators: resistance to central catecholamine depletion, increased peripheral catecholamine availability, increased beta-receptor sensitivity, and suppression of cortisol responses. From the research constituting that nomological net, it was possible to identify parameters of timing; the importance of low arousal base rates with strong and responsive SNS-adrenal-medullary arousal (to challenge or threat) followed by quick decline was emphasized. Relations between those physiological parameters and positive performance, temperament, and immune system characteristics were explicated.

In the theoretical perspective developed to account for these relations, I considered the evidence that the requirements for mental coping are provided primarily by adrenaline (blood glucose and adequate brain blood circulation); requirements for physical coping are supplied to a greater extent by noradrenaline. With a toughened arousal capability, the availability of sufficient energy to cope mentally or physically without great effort or exhaustion is a resource taken into account in the appraisal process; those more positive appraisals in turn ensure that the pattern of arousal associated with toughness is generated, which provides the energy necessary for coping at minimal psychological and physiological cost. The person who experiences this positive syndrome of interaction between energy-generating arousal and positive attributions is more likely to enjoy challenging mental and physical activities and, therefore, to seek them out. Another interactive sequence is then entered, as the tough individual increasingly seeks the very experiences that may lead to toughening.

\section{Therapy Issues}

Positive views of arousal have had minimal impact on systems of therapy. This lack of integration may reflect in part a lack of awareness of established literatures, as reflected in Houston's (1986) statement that "few studies on relationships between enduring psychological characteristics and neuroendocrine reactivity have been done apart from those on the Type A behavior pattern" (p. 208). A more likely explanation for underrepresentation of concepts such as toughening may be that they are not directly suggested by typical laboratory or clinical observations.

When research subjects are exposed to manipulations that they cannot control (such as disturbing movies, cold pressors, noise, and shock), normal coping responses may be unproductive. Arousal may therefore be neither adaptive for the subject nor positively regarded by the researcher. As with continuous but uncontrollable stressors (such as living near Three Mile Island), the most adaptive responses may be palliative coping: control of emotional response. (Contrast the manipulations of the Scandinavian researchers, in which active coping could occur and arousal was regarded more positively.)

A similar view of arousal and coping is available to the therapist. The client who cannot overcome stressful situations is thereby doomed to live among them, possibly with consistently elevated arousal. It is therefore apparently sensible for the therapist to initiate relaxation-based therapies, directed toward the cli- 
ent's inadequacies in achieving a low arousal base rate or quick decline in arousal, and it is unlikely that therapists will consider toughening procedures that address inadequacies in achieving a strong arousal spike.

This model suggests that an important part of adequate longterm coping depends on physiological toughness. Relaxationbased therapies (biofeedback, autogenic training, meditation, chemical tranquilizers, etc.) provide short-term solutions that may foster avoidance of the very situations that lead to toughness. With respect to chemical tranquilizers, Gray (1981, 1983) noted that in animal research, a single dose of tranquilizer leads to the same behavioral changes in the short term that a program of toughening manipulations lead to in the long term; but if tranquilizers are given during toughening procedures, the tranquilizers prevent toughening and the associated positive benefits. Gray suggested that if humans respond to toughening procedures as nonhumans do, the long-term cost of the use of tranquilizers would be high (1981, p. 396). Similar short-term benefits and long-term costs have been noted for beta blockers (Dimsdale, Alpert, \& Schneiderman, 1986).

From the nomological net developed here, it is apparent that nonhuman and human responses to toughening procedures are comparable. But danger from therapeutic tranquilization goes beyond the potential overuse of chemical agents; the overuse of mental (or behavioral) relaxation techniques leads to analogous problems (see also Dimsdale et al., 1986). However, even when they include training in psychological coping skills, relaxationbased therapies are at best a start in an effective stress-control program.

\section{Life-Style Issues}

Of the several manipulations discussed, few are appropriate for therapy or for life patterns that might lead to toughening. Social stressors are inappropriate for a host of obvious reasons and because they may not lead to toughening if they were used. Remember that when nonhumans are exposed to chronic social stressors (in contrast to physical stressors), benefits to their immune systems do not result (Sklar \& Anisman, 1981). Psychologically, it may be that social stressors are too continuous, preventing toughening by allowing insufficient intervals for recovery.

Another potential toughening manipulation is regular exposure to mental challenge. But substantial numbers of researchers have not yet tested whether mental challenge may be effective. It is possible that sufficient mental stimulation is typically available in technologically advanced societies so that toughening through increased mental stimulation would provide diminished returns. If it were effective, modifying the amount of challenge in our lives may be difficult because we are often confined by limiting life circumstances and occupations. Some research (which should be considered preliminary) by Karasek et al. (1982) has suggested that high levels of occupational demands in combination with high control (an adequate "challenge" definition) may lead to many of the physiological changes (e.g., lower arousal base rates) associated with toughness.

The reliable elicitation of catecholamine responses by humor (Fry, 1986) suggests the usefulness of humor as a toughening procedure when, as with bedridden patients, more vigorous (and presumably more effective) responses are not possible.

Regular exposure to cold temperatures is a passive toughening manipulation that leads to many of the physiological effects that are also associated with exercise programs (e.g., LeBlanc, Dulac, Côté, \& Girard, 1975). Temperature tolerance (especially cold tolerance) also correlates with the performance and personality characteristics associated with the tough individual (Dienstbier, LaGuardia, \& Wilcox, 1987). But it seems unlikely that many citizens of technologically sophisticated societies (aside from skiers, ice skaters, etc.) will voluntarily expose themselves to low temperatures in order to toughen.

Instead, the more obvious avenue toward toughening is a program of aerobic exercise. In contrast to the high level of mental challenge available (to many) in technologically advanced environments, advanced civilization (like the living conditions for lab animals) has led to dramatic underuse of human physical abilities. Even modest physical training programs should therefore have an impact on toughening. Research reviewed earlier affirmed that exercise training builds toughness that is relevant to either physical or mental challenge/threat situations.

The physiological benefits demonstrated from exercise programs include all of those linked with toughening: for example, lower arousal base rates, including heart rate and blood pressure (E. Baum et al., 1976), quicker return to arousal base rate after stress, improved glucose utilization, and more circulating monocytes (active in resisting bacterial infection; Keller \& Seraganian, 1984). Physiological benefits not emphasized by this system are also achieved: for example, relative increases in high density lipoprotein ("good" cholesterol) with lower serum triglyceride levels.

Potential direct psychological benefits from a successful exercise program include feelings of mastery or "effectance" and of improved body image (exercise usually results in lowered weight "set points" for both humans and nonhumans). Exercise is also useful in relieving physiological arousal after acute stress. An episode of exercise reduces muscle tension (deVries, 1968), lowers SNS arousal indicators to stressful stimuli induced even hours later (a situation in which arousal-supported coping is clearly not adaptive; Dienstbier et al., 1981), lowers free fatty acids in blood (Norum \& Ursin, 1978), and lowers self-reports of anxiety and tension (for a review, see Morgan, 1976).

\section{Concluding Comment}

In his final work, Bateson (1979) developed a useful conceptualization of adaptation as behavioral, somatic, or genetic. During a short-term environmental change, behavioral responses (e.g., panting at high altitudes) allow maximum flexibility. Somatic change within genetic limits (e.g., acclimatization of blood to altitude) allows less flexibility but is more effective in a stable environment. However, when somatic adaptation forces an organ or a system to function near one of the extremes allowed by genetic limits, the other systems with which the adapted system interacts are likely to be strained. Without the operation of natural selection, genetic adaptation will not relieve this strain in future generations.

Applying that framework to the issues of this article leads to 
the following: Life in a mechanized world can easily result in insufficient physical demands, so that natural toughening is not fostered, and the neuroendocrine systems associated with arousal are not maintained near the optimum point of their genetic ranges. Strains are therefore likely for related systems. Obvious manifestations of such strain include weight control problems, poor muscle tone, and poor endurance in physical coping. Less obvious manifestations suggested by this model include poor psychological coping endurance (stress tolerance), susceptibility to anxiety and depression, attention and learning deficits, susceptibility to cardiovascular diseases, and reduced immune capacity.

\section{References}

Alho, H., Koistinaho, J., Kovanen, V., Suominen, H., \& Hervonen, A. (1984). Effect of prolonged physical training on the histochemically demonstrable catecholamines in the sympathetic neurons, the adrenal gland and extra-adrenal catecholamine storing cells of the rat. Journal of the Autonomic Nervous System, 10, 181-191.

Anisman, H., \& LaPierre, Y. (1982). Neurochemical aspects of stress and depression: Formulations and caveats. In R. W. Neufeld (Ed.), Psychological stress and psychopathology (pp. 179-217). New York: McGraw-Hill.

Baade, E., Ellertsen, B., Johnsen, T. B., \& Ursin, H. (1978). Physiology, psychology, and performance. In H. Ursin, E. Baade, \& S. Levine (Eds.), Psychobiology of stress: A study of coping men (pp. 163182). New York: Academic Press.

Bandura, A., Reese, L., \&Adams, N. E. (1982). Microanalysis of action and fear arousal as a function of differential levels of perceived selfefficacy. Journal of Personality and Social Psychology, 43, 5-21.

Barnes, D. M. (1986). Steroids may influence changes in mood. Science, $232,1344-1345$.

Bass, C. (1984). Type A behavior: Recent developments. Journal of Psychosomatic Research, 28, 371-378.

Bateson, G. (1979). Mind and nature: A necessary unity. London: Fontana Paperbacks.

Baum, A. S. (1986, August). Chronic and extreme stress: Psychobiological influences on health. Paper presented at the annual meeting of the American Psychological Association, Washington, DC.

Baum, E., Brück, K., \& Schwennicke, H. P. (1976). Adaptive modifications in the thermoregulatory system of long-distance runners. Journal of Applied Physiology, 40, 404-410.

Bhagat, B. D., \& Horenstein, S. (1976). Modulation of adrenal medullary enzymes by stress. In E. Usdin, R. Kvetnansky, \& I. J. Kopin (Eds.), Catecholamines and stress (pp. 257-264). Oxford, England: Pergamon.

Blumenthal, J. A., Williams, R. S., Williams, R. B. Jr., \& Wallace, A. G. (1980). Effects of exercise on the Type A (coronary prone) behavior pattern. Psychosomatic Medicine, 42, 289-296.

Booth-Kewley, S., \& Friedman, H. S. (1987). Psychological predictors of heart disease: A quantitative review. Psychological Bulletin, 101, $343-362$.

Brod, J. (1970). Haemodynamics of emotional stress. In M. Koster, H. Musaph, \& P. Viser (Eds.), Psychosomatics in essential hypertension (pp. 13-37). Basel, Switzerland: S. Karger.

Brown, B. S., Payne, T., Kim, C., Moore, G., Krebs, P., \& Martin, W. (1979). Chronic response of rat brain norepinephrine and serotonin levels to endurance training. Journal of Applied Physiology, 46, $19-23$.
Brown, B. S., \& Van Huss, W. (1973). Exercise and rat brain catecholamines. Journal of Applied Physiology, 34, 664-669.

Bryar, B. A., Fregly, M. J., \& Field, F. P. (1983). Changes in vascular responsiveness following chronic exposure to cold in the rat. Journal of Applied Physiology, 55, 823-829.

Calabrese, J. R., Kling, M. A., \& Gold, P. W. (1987). Alterations in immunocompetence during stress, bereavement, and depression: Focus on neuroendocrine regulation. American Journal of Psychiatry, 144, $1123-1134$

Cannon, W. B. (1929). Bodily changes in pain, hunger, fear, and rage. Boston: Branford. (Original work published 1915)

Carruthers, M. (1981). 'Field studies': Emotion and beta-blockade. In M. J. Christie \& P. G. Mellett (Eds.), Foundations of psychosomatics (pp. 223-241). Chichester, England: Wiley.

Clarkson, T. B., Manuck, S. B., \& Kaplan, J. R. (1986). Potential role of cardiovascular reactivity in atherogenesis. In K. A. Matthews, S. M. Weiss, T. Detre, T. M. Dembroski, B. Falkner, S. B. Manuck, \& R. B. Williams, Jr. (Eds.), Handbook of stress, reactivity and cardiovascular disease (pp. 35-48). New York: Wiley.

Collins, D. L., Baum, A., \& Singer, J. E. (1983). Coping with chronic stress at Three Mile Island: Psychological and biochemical evidence. Health Psychology, 2, 149-166.

Coover, G. D., Ursin, H., \& Murison, R. (1983). Sustained activation and psychiatric illness. In H. Ursin \& R. Murison (Eds.), Biological and psychological basis of psychosomatic disease (pp. 249-258). Oxford, England: Pergamon.

Denenberg, V. H. (1967). Stimulation in infancy, emotional reactivity, and exploratory behavior. In D. C. Glass (Ed.), Neurophysiology and emotion (pp. 161-190). New York: Rockefeller University Press.

deVries, H. A. (1968). Immediate and long-term effects of exercise upon resting muscle action potential. Journal of Sports Medicine and Physical Fitness, 8, 1-11.

Dienstbier, R. A. (1979). Emotion-attribution theory: Establishing roots and exploring future perspectives. In H. E. Howe, Jr., \& R. A. Dienstbier (Eds.), Nebraska Symposium on Motivation: Human emotion (Vol. 27, pp. 237-306). Lincoln: University of Nebraska Press.

Dienstbier, R. A. (1984). The effect of exercise on personality. In M. L. Sachs \& G. B. Buffone (Eds.), Running as therapy: An integrated approach (pp. 253-272). Lincoln: University of Nebraska Press.

Dienstbier, R. A., Crabbe, J., Johnson, G. O., Thorland, W., Jorgensen, J. A., Sadar, M. M., \& Lavelle, D. C. (1981). Exercise and stress tolerance. In M. H. Sacks \& M. L. Sachs (Eds.), Psychology of running (pp. 192-210). Champaign, IL: Human Kinetics Publishers.

Dienstbier, R. A., LaGuardia, R. L., Barnes, M., Tharp, G., \& Schmidt, R. (1987). Catecholamine training effects from exercise programs: A bridge to exercise-temperament relationships. Motivation and Emotion, 11, 297-318.

Dienstbier, R. A., LaGuardia, R. L., \& Wilcox, N. S. (1987). The relationship of temperament to tolerance of cold and heat: Beyond "cold hands-warm heart." Motivation and Emotion, 11, 269-295.

Dimsdale, J. E., Alpert, B. S., \& Schneiderman, N. (1986). Exercise as a modulator of cardiovascular reactivity. In K. A. Matthews, S. M. Weiss, T. Detre, T. M. Dembroski, B. Falkner, S. B. Manuck, \& R. B. Williams, Jr. (Eds.), Handbook of stress, reactivity and cardiovascular disease (pp. 365-384). New York: Wiley.

Donovan, B. T. (1985). Hormones and human behaviour. Cambridge, England: Cambridge University Press.

Ehsani, A. A., Heath, G. W., Martin, W. H. III, Hagberg, J. M., \& Holloszy, J. O. (1984). Effects of intense exercise training on plasma cate- 
cholamines in coronary patients. Journal of Applied Physiology, 57, $154-159$

Eide, R., \& Atterås, A. (1978). Blood glucose. In H. Ursin, E. Baade, \& S. Levine (Eds.), Psychobiology of stress: A study of coping men (pp. 99-103). New York: Academic Press.

Ellertsen, B., Johnsen, T. B., \& Ursin, H. (1978). Relationship between the hormonal responses to activation and coping. In H. Ursin, E. Baade, \& S. Levine (Eds.), Psychobiology of stress: A study of coping men (pp. 105-124). New York: Academic Press.

Eysenck, H. J. (1983a). Psychophysiology and personality: Extraversion, neuroticism and psychoticism. In A. Gale \& I. A. Edwards (Eds.), Physiological correlates of human behavior, Vol. III; Individual differences and psychopathology (pp. 13-30). London: Academic Press.

Eysenck, H. J. (1983b). Stress, disease, and personality: The 'inoculation effect.' In C. L. Cooper (Ed.), Stress research; Issues for the eighties (pp. 121-146). Chichester, England: Wiley.

Faucheau, B. A., Bourliere, F., Baulon, A., \& Dupuis, C. (1981). The effects of psychosocial stress on urinary excretion of adrenaline and noradrenaline in 51- to 55- and 71- to 74-year-old men. Gerontology, 27, 313-325.

Folkman, S. (1984). Personal control and stress and coping processes: A theoretical analysis. Journal of Personality and Social Psychology, 46, 839-852.

Folkman, S., \& Lazarus, R. S. (1985). If it changes it must be a process: Study of emotion and coping during three stages of a college examination. Journal of Personality and Social Psychology, 48, 150-170.

Forsman, L. (1981). Habitual catecholamine excretion and its relation to habitual distress. Biological Psychology, 11, 83-97.

Forsman, L. (1983). Individual and group differences in psychophysiological responses to stress - With emphasis on sympathetic-adrenal medullary and pituitary-adrenal cortical responses. Unpublished doctoral dissertation, University of Stockholm, Stockholm, Sweden.

Frankenhaeuser, M. (1979). Psychoneuroendocrine approaches to the study of emotion as related to stress and coping. In H. E. Howe, Jr., \& R. A. Dienstbier (Eds.), Nebraska Symposium on Motivation, 1978; Human emotion (Vol. 27, pp. 123-161). Lincoln: University of Nebraska Press.

Frankenhaeuser, M., Lundberg, U., \& Forsman, L. (1980). Dissociation between sympathetic-adrenal and pituitary-adrenal responses to an achievement situation characterized by high controllability: Comparison between Type A and Type B males and females. Biological Psychology, 10, 79-91.

Frankenhaeuser, M., \& Poitkai, P. (1965). Interindividual differences in catecholamine excretion during stress. Scandinavian Journal of Psychology, 6, 117-123.

Fry, W. F. Jr. (1986). Humor, physiology, and the aging process. In L. Nahemow, K. A. McCluskey-Fawcett, \& P. E. McGhee (Eds.), Humor and aging (pp. 91-98). Orlando, FL: Academic Press.

Gal, R., \& Lazarus, R. S. (1975). The role of activity in anticipating and confronting stressful situations. Journal of Human Stress, 1, 4-20.

Ganong, W. F., Kramer, N., Reid, I. A., Boryczka, A. T., \& Shackelford, R. (1976). Inhibition of stress-induced ACTH secretion by norepinephrine in the dog; Mechanism and site of action. In E. Usdin, R. Kvetnansky, \& I. J. Kopin (Eds.), Catecholamines and stress (pp. 139-144). Oxford, England; Pergamon.

Garmezy, N. (1983). Stressors of childhood. In N. Garmezy \& M. Rutter (Eds.), Stress, coping and development in children (pp. 43-84). New York: McGraw-Hill.

Glazer, H. I., Weiss, I. M., Pohorecky, L. A., \& Miller, N. E. (1975).
Monoamines as mediators of avoidance-escape behavior. Psychosomatic Medicine, 37, 535-543.

Gold, P. E. (1986). Glucose modulation of memory storage processing. Behavioral and Neural Biology, 45, 342-349.

Gold, P. E.. \& Delanoy, R. L. (1981). ACTH modulation of memory storage processing. In I. L. Martinez Jr., R. A. Jensen, R. B. Messing, H. Rigter, \& J. L. McGaugh (Eds.), Endogenous peptides and learning and memory processes (pp. 79-98). New York: Academic Press.

Goldstein, D. S., \& McDonald, R. H. (1986). Biochemical indices of cardiovascular reactivity. In K. A. Matthews, S. M. Weiss, T. Detre, T. M. Dembroski, B. Falkner, S. B. Manuck, \& R. B. Williams, Jr. (Eds.), Handbook of stress, reactivity, and cardiovascular disease (pp. 187-203). New York: Wiley.

Gray, J. A. (1981). The physiopsychology of anxiety. Oxford, England: Oxford University Press.

Gray, J. A. (1983). Anxiety, personality and the brain. In A. Gale \& J. A. Edwards (Eds.), Physiological correlates of human behavior, Vol. III: Individual differences and psychopathology (pp. 31-43). London: Academic Press.

Greenberg, L. H., \& Wiess, B. (1978). Beta-adrenergic receptors in aged rat brain: Reduced number and capacity of pineal gland to develop supersensitivity. Science, 201, 61-63.

Halse, K., Blix, A. S., Ellertsen, B., \& Ursin, H. (1978). Development of performance and fear experience. In H. Ursin, E. Baade, \& S. Levine (Eds.), Psychobiology of stress: A study of coping men (pp. 41-50). New York: Academic Press.

Harri, M. N. E. (1979). Physical training under the influence of betablockade in rats: II. Effects on vascular reactivity. (1979). European Journal of Applied Physiology, 42. 151-157.

Henry, J. P., Kross, M. E., Stephens, P. M., \& Watson, F. M. C. (1976). Evidence that differing psychosocial stimuli lead to adrenal cortical stimulation by autonomic or endocrine pathways. In E. Usdin, R. Kvetnansky, \& I. J. Kopin (Eds.), Catecholamines and stress (pp. 457-468). Oxford, England: Pergamon.

Herd, J. A. (1986). Neuroendocrine mechanisms in coronary heart disease. In K. A. Matthews, S. M. Weiss, T. Detre, T. M. Dembroski, B. Falkner, S. B. Manuck, \& R. B. Williams, 1r. (Eds.), Handbook of stress. reactivity, and cardiovascular disease (pp. 49-70). New York: Wiley.

Holmes, T. H., \& Rahe, R. H. (1967). The social readjustment rating scale. Journal of Psychosomatic Research, 11, 213-218.

Houston, B. K. (1986). Psychological variables and cardiovascular and neuroendocrine reactivity. In K. A. Matthews, S. M. Weiss, T. Detre, T. M. Dembroski, B. Falkner, S. B. Manuck, \& R. B. Williams Jr. (Eds.), Handbook of stress, reactivity, and cardiovascular disease (pp. 207-229). New York: Wiley.

Hull, E., Young, S., \& Ziegler, M. (1984). Aerobic fitness affects cardiovascular and catecholamine responses to stressors. Psychophysiology, 21, 253-260.

Hunt, J. McV. (1965). Traditional personality theory in the light of recent evidence. American Scientist, 53, 80-96.

Jansky, L., Mejsnar, J., \& Moravec, J. (1976). Catecholamines and cold stress. In E. Usdin, R. Kvetnansky, \& I. J. Kopin (Eds.), Catecholamines and stress (pp. 419-434). Oxford, England: Pergamon.

Johansson, G., \& Frankenhaeuser, J. (1973). Temporal factors in sympatho-adrenomedullary activity following acute behavioral activation. Biological Psychology, 1, 63-73.

Johansson, G., Frankenhaeuser, M., \& Magnusson, D. (1973). Catecholamine output in school children as related to performance and adjustment. Scandinavian Journal of Psychology, 14, 20-28. 
Karasek, R. A., Russell, R. S., \& Theorell, T. (1982). Physiology of stress and regeneration in job related cardiovascular illness. Journal of Human Stress, 8, 29-42.

Kasl, S. V. (1983). Pursuing the link between stressful life experiences and disease: A time for reappraisal. In C. L. Cooper (Ed.), Stress research: Issues for the eighties (pp. 79-102). New York: Wiley.

Keller, S., \& Seraganian, P. (1984). Physical fitness level and autonomic reactivity to psychosocial stress. Journal of Psychosomatic Research, 28, 279-287.

Knardahl, S., \& Ursin, H. (1985). Sustained activation and the pathophysiology of hypertension and coronary heart disease. In J. F. Orlebeke, G. Mulder, \& L. J. P. van Doornen (Eds.), Psychophysiology of cardiovascular control (pp. 151-167). New York: Plenum.

Knight, R. B., Atkins, A., Eagle, C. J., Evans, N., Finkelstein, J. W., Fukushima, D., Katz, J., \& Weiner, H. (1979). Psychological stress, ego defenses, and cortisol production in children hospitalized for elective surgery. Psychosomatic Medicine, 41, 40-49.

Krotkiewski, M., Mandroukas, K., Morgan, L., William-Olsson, T., Feurle, G. E., von Schenck, H., Bjorntorp, P., Sjostrom, L., \& Smith, U. (1983). Effects of physical training on adrenergic sensitivity in obesity. Journal of Applied Physiology, 55, 1811-1817.

Lader, M. (1983). Anxiety and depression. In A. Gale \& J. A. Edwards (Eds.), Physiological correlates of human behavior, Vol. III: Individual differences and psychopathology (pp. 155-167). London: Academic Press.

Lazarus, R. S. (1968). Emotions and adaptation: Conceptual and empirical relations. In W. J. Arnold (Ed.), Nebraska Symposium on Motivation (Vol. 16, pp. 175-266). Lincoln: University of Nebraska Press.

LeBlanc, J. (1976). The role of catecholamines in adaptation to chronic and acute stress. In E. Usdin, R. Kvetnansky, \& I. J. Kopin (Eds.), Catecholamines and stress (pp. 409-418). Oxford, England: Pergamon.

LeBlanc, J., Boulay, M., Dulac, S., Jobin, M., Labrie, A., \& RousseauMigneron, S. (1977). Metabolic and cardiovascular responses to norepinephrine in trained and nontrained human subjects. Journal of Applied Physiology, 42, 166-173.

LeBlanc, J., Côté, J., Dulac, S., \& Dulong-Turcot, F. (1978). Effects of age, sex, and physical fitness on responses to local cooling. Journal of Applied Physiology, 44, 813-817.

LeBlanc, J., Côté, J., Jobin, M., \& Labrie, A. (1979). Plasma catecholamines and cardiovascular responses to cold and mental activity. Journal of Applied Physiology, 47, 1207-1211.

LeBlanc, J., Dulac, S., Côté, J., \& Girard, B. (1975). Autonomic nervous system and adaptation to cold in man. Journal of Applied Physiology, 39, 181-186.

Levine, S. (1960). Stimulation in infancy. Scientific American, 202, 8086.

Levine, S. (1978). Cortisol changes following repeated experiences with parachute training. In H. Ursin, E. Baade, \& S. Levine (Eds.), Psychobiology of stress: A study of coping men (pp. 51-56). New York: Academic Press.

Levine, S. (1980). A coping model of mother-infant relationships. In S. Levine \& H. Ursin (Eds.), Coping and health (pp. 87-100). New York: Plenum.

Levine, S. (1983). Coping: An overview. In H. Ursin \& R. Murison (Eds.), Biological and psychological basis of psychosomatic disease. Oxford, England: Pergamon.

Lundberg, U., \& Forsman, L. (1979). Adrenal-medullary and adrenalcortical responses to understimulation and overstimulation: Comparison between Type A and Type B persons. Biological Psychology, 9,
$79-89$.

Lundberg, U., \& Frankenhaeuser, M. (1980). Pituitary-adrenal and sympathetic-adrenal correlates of distress and effort. Journal of Psychosomatic Research, 24, 125-130.

Manuck, S. B., \& Krantz, D. S. (1986). Psychophysiologic reactivity in coronary heart disease and essential hypertension. In K. A. Matthews, S. M. Weiss, T. Detre, T. M. Dembroski, B. Falkner, S. D. Manuck, \& R. B. Williams, Jr. (Eds.), Handbook of stress, reactivity and cardiovascular disease (pp. 11-34). New York: Wiley.

Martin, C. R. (1985). Endocrine physiology. New York: Oxford University Press.

Matthews, K. A. (1986). Summary, conclusions, and implications. In K. A. Matthews, S. M. Weiss, T. Detre, T. M. Dembroski, B. Falkner, S. B. Manuck, \& R. B. Williams, Jr. (Eds.), Handbook of stress, reactivity, and cardiovascular disease (pp. 461-473). New York: Wiley.

Matthews, K. A., Weiss, S. M., Detre, T., Dembroski, T. M., Falkner, B., Manuck, S. B., \& Williams, R. B., Jr. (Eds.), (1986). Handbook of stress, reactivity, and cardiovascular disease. New York: Wiley.

McCann, I. L., \& Holmes, D. S. (1984). Influence of aerobic exercise on depression. Journal of Personality and Social Psychology, 46, 11421147.

McCarty, R. (1985). Sympathetic-adrenal medullary and cardiovascular responses to acute cold stress in adult and aged rats. Journal of the Autonomic Nervous System, 12, 15-22.

McGaugh, J. L. (1983). Preserving the presence of the past: Hormonal influences on memory storage. American Psychologist, 38, 161-174.

McNeal, E. T., \& Cimbolic, P. (1986). Antidepressants and biochemical theories of depression. Psychological Bulletin, 99, 361-374.

Meaney, M. J., Aitkens, D. H., Berkel, C., Bhatnagar, S., Sarrieau, A., \& Sapolsky, R. M. (1987, November). Post-natal handling attenuates age-related changes in the adrenocortical stress response and spatial memory deficits in the rat. Paper presented at the 17th Annual Meeting of the Society of Neuroscience, New Orleans.

Miller, N. E. (1980). A perspective on the effects of stress and coping on disease and health. In S. Levine \& H. Ursin (Eds.), Coping and health (pp. 323-354). New York: Plenum.

Morgan, W. P. (1976). Psychological consequences of vigorous physical activity and sport. Annals of the New York Academy of Science, 301, $15-30$.

Norum, K., \& Ursin, H. (1978). Fatty acid mobilization. In H. Ursin, E. Baade, \& S. Levine (Eds.), Psychobiology of stress: A study of coping men (pp. 75-82). New York: Academic Press.

O'Hanlon, J. F., \& Beatty, J. (1976). Catecholamine correlates of radar monitoring performance. Biological Psychology, 4, 293-304.

Overmier, J. B., \& Seligman, M. E. P. (1967). Effects of inescapable shock upon subsequent escape and avoidance learning. Journal of Comparative and Physiological Psychology, 63, 28-33.

Persky, H. (1975). Adrenocortical function and anxiety. Psychoneuroendocrinology, 1, 37-44.

Pfeifer, W. D. (1976). Modification of adrenal tyrosine hydroxylase activity in rats following manipulation in infancy. In E. Usdin, R. Kvetnansky, \& I. J. Kopin (Eds.), Catecholamines and stress (pp. 265270). Oxford, England: Pergamon.

Potter, W. Z., Ross, R. J., \& Zavadil, A. P. Ill. (1985). Norepinephrine in the affective disorders: Classic biochemical approaches. In C. R. Lake \& M. a. Ziegler (Eds.), The catecholamines in psychiatric and neurologic disorders (pp. 213-233). Boston: Butterworth.

Rabkin, J. G., \& Struening, E. L. (1976). Life events, stress, and illness. Science, 194, 1013-1020. 
Rauste-von Wright, M., von Wright, J., \& Frankenhaeuser, M. (1981). Relationships between sex-related psychological characteristics during adolescence and catecholamine excretion during achievement stress. Psychophysiology, 18, 362-370.

Ritter, S., \& Pelzer, N. L. (1978). Magnitude of stress-induced brain norepinephrine depletion varies with age. Brain Research, 152, 170175.

Rodin, J. (1980). Managing the stress of aging: The role of control and coping. In S. Levine \& H. Ursin (Eds.), Coping and health (pp. 171202). New York: Plenum.

Roessler, R., Burch, N. R., \& Mefferd, R. B. (1967). Personality correlates of catecholamine excretion under stress. Journal of Psychosomatic Research, 11, 181-185.

Rose, R. M., Poe, R. O., \& Mason, J. W. (1967). Observations on the relationship between psychological state, 17-OHCS excretion, and epinephrine, norepinephrine, insulin, BEI, estrogen and androgen levels during basic training. Psychosomatic Medicine, 29, 544.

Sartory, G., \& Lader, M. (1981). Psychophysiology and drugs in anxiety and phobias. In M. J. Christie \& P. G. Mellett (Eds.), Foundations of psychosomatics (pp. 169-192). Chichester, England: Wiley.

Selye, H. (1956). The stress of life. New York: McGraw-Hill.

Sinyor, D., Schwartz, S. G., Peronnet, F., Brisson, G., \& Seraganian, P. (1983). Aerobic fitness level and reactivity to psychosocial stress: Physiological, biochemical, and subjective measures. Psychosomatic Medicine, 45, 205-217.

Sklar, L. S., \& Anisman, H. (1981). Stress and cancer. Psychological Bulletin, 89, 369-406.

Smith, C. U. M. (1970). The brain. New York: Putnam.

Smith, T. W., \& Anderson, N. B. (1986). Models of personality and disease: An interactional approach to Type A behavior and cardiovascular risk. Journal of Personality and Social Psychology, 50, 11661173.

Solomon, G. S., Kay, N., \& Morley, J. E. (1986). Endorphins: A link between penality, stress, emotions, immunity, and disease? In N. P. Plotnikoff, R. E. Faith, A. J. Murgo, \& R. A. Good (Eds.), Enkephalins and endorphins: Stress and the immune system (pp. 129-144). New York: Plenum.

Solomon, R. L., \& Wynne, L. C. (1954). Traumatic avoidance learning: The principles of anxiety conservation and partial irreversibility. Psychological Review, 61, 353-385.

Starzec, J. J., Berger, D. F., \& Hesse, R. (1983). Effects of stress and exercise on plasma corticosterone, plasma cholesterol, and aortic cholesterol levels in rats. Psychosomatic Medicine, 45, 219-226.

Stone, E. A. (1968). The effects of emotionality on thermoregulation during stress. Dissertation Abstracts International, 28, 4785B. (University Microfilms No. 68-6857)

Theorell, T. (1976). Selected illnesses and somatic factors in relation to two psychosocial stress indices: A prospective study on middle-aged construction building workers. Journal of Psychosomatic Research, 20(7).

Thoits, P. A. (1983). Dimensions of life events that influence psychological distress: An evaluation and synthesis of the literature. In H. B. Kaplan (Ed.), Psychosocial stress: Trends in theory and research (pp. 33-103). New York: Academic Press.

Thorsrud, E. (1983). Coping with normal and critical situations in offshore oil activity. In H. Ursin \& R. Murison (Eds.), Biological and psychological basis of psychosomatic disease. Oxford, England: Pergamon.
Ursin, H. (1978). Activation, coping, and psychosomatics. In H. Ursin, E. Baade, \& S. Levine (Eds.), Psychobiology of stress: A study of coping men (pp. 201-228). New York: Academic Press.

Ursin, H., Baade, E., \& Levine, S. (Eds.). (1978). Psychobiology of stress: A study of coping men. New York: Academic Press.

Ursin, H., \& Knardahl, S. (1985). Personality factors, neuroendocrine response patterns, and cardiovascular pathology. In J. F. Orlebeke, G Mulder, \& L. J. P. van Doornen (Eds.), Psychophysiology of cardiovascular control (pp. 715-731). New York: Plenum.

Ursin, H., Murison, R., \& Knardahl, S. (1983). Conclusion: Sustained activation and disease. In H. Ursin \& R. Murison (Eds.), Biological and psychological basis of psychosomatic disease (pp. 269-277). Oxford, England: Pergamon.

Ursin, H., Mykletun, R., Tønder, O., Vaernes, R., Relling, G., Isaksen, E., \& Murison, R. (1984). Psychological stress-factors and concentrations of immunoglobulins and complement components in humans. Scandinavian Journal of Psychology, 25, 340-347.

Vaernes, R., Ursin, H., Darragh, A., \& Lambe, R. (1982). Endocrine response patterns and psychological correlates. Journal of Psychosomatic Research, 26, 123-131.

van Praag, H. M. (1986). Monoamines and depression: The present state of the art. In R. Plutchik \& H. Kellerman (Eds.), Emotion: Theory, research, and experience. Volume 3: Biological foundations of emotion (pp. 335-361). Orlando, FL: Academic Press.

Ward, M. M., Mefford, I. N., Parker, S. D., Chesney, M. A., Taylor, C. B., Keegan, D. L., \& Barchas, J. D. (1983). Epinephrine and norepinephrine responses in continuously collected human plasma to a series of stressors. Psychosomatic Medicine, 45, 471-486.

Weiss, J. M., \& Glazer, H. I. (1975). Effects of acute exposure to stressors on subsequent avoidance-escape behavior. Psychosomatic Medicine, 37, 499-521.

Weiss, J. M., Glazer, H. I., Pohorecky, L. A., Brick, J., \& Miller, N. E. (1975). Effects of chronic exposure to stressors on avoidance-escape behavior and on brain norepinephrine. Psychosomatic Medicine, 37, 522-534.

Weiss, J. M., Stone, E. A., \& Harrell, N. (1970). Coping behavior and brain norepinephrine level in rats. Journal of Comparative and Physiological Psychology, 72, 153-160.

Whybrow, P. C., \& Silberfarb, P. M. (1977). Neuroendocrine mediating mechanisms: From the symbolic stimulus to the physiological response. In Z. J. Lipowski, D. R. Lipsitt, \& P. C. Whybrow (Eds.), Psychosomatic medicine: Current trends and clinical applications. New York: Oxford University Press.

Williams, R. B., Jr. (1986, August). Beyond Type A: Psychological and physiological refinements. Paper presented at the annual meeting of the American Psychological Association, Washington, DC.

Williams, R. S., Caron, M. G., \& Daniel, K. (1984). Skeletal muscle betaadrenergic receptors: Variations due to fiber type and training. American Journal of Physiology, 246, E160-E167.

Williams, R. S., Eden, R. S., Moll, M. E., Lester, R. M., \& Wallace, A. G. (1981). Autonomic mechanisms of training bradycardia: Beta-adrenergic receptors in humans. Journal of Applied Physiology, 51, 1232 1237.

Submitted January 1987; revised April 1988; accepted April 13, 1988 